\title{
Saphata dalam Beberapa Prasasti
}

\section{Rita Istari}

Keywords: inscription, literature, transliteration, transcription, java, bali

\section{How to Cite:}

Istari, R. (2007). Saphata dalam Beberapa Prasasti. Berkala Arkeologi, 27(1), 43-52. https://doi.org/10.30883/jba.v27i1.942

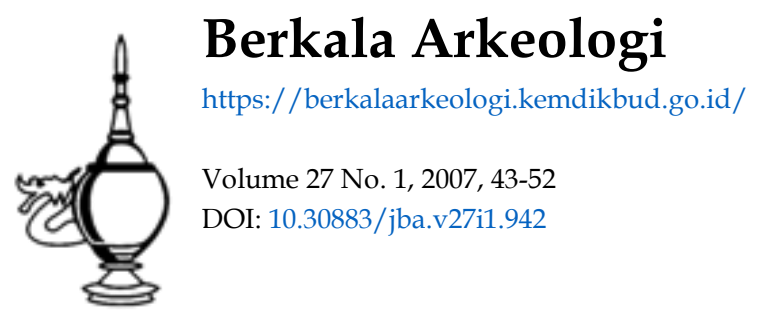

\section{c) (1) (5)}

This work is licensed under a Creative Commons Attribution-NonCommercial-ShareAlike 4.0 International License. 


\title{
Saphata dalam Beberapa Prasasti
}

\author{
T.M. Rita Istari \\ (Balai Arkeologi Yogyakarta)
}

\section{Pendahuluan}

Dalam penulisan sejarah kuna Indonesia, diperlukan tidak hanya sumbersumber sejarah berupa benda-benda peninggalan masa lampau/artefak, tetapi juga berupa sumber-sumber tertulis yang salah satu diantaranya adalah prasasti. Dalam pengertian arkeologi, prasasti merupakan piagam resmi kerajaan yang dipahatkan di atas batu atau lempengan logam, biasanya berisi keputusan. mengenai penetapan suatu daerah menjadi sima/daerah perdikan. Penetapan suatu daerah menjadi sima oleh seorang raja atau keluarga, biasanya dilakukan apabila daerah tersebut dianggap berjasa dan untuk kepentingan suatu bangunan suci. Akan tetapi, terdapat juga prasasti yang berisi tentang keputusan pengadilan dan hukum. Selain pada batu dan logam, tulisan kuna dapat juga dituliskan pada lontar, gerabah, arca, dan mungkin juga benda-benda lain yang mudah lapuk seperti bambu dan kayu, sehingga tidak dijumpai lagi sekarang.

Keputusan mengenai penetapan sima biasanya disahkan melalui suatu upacara yang unsur-unsurnya tertulis dalam prasasti. Salah satu unsur upacara yang terdapat pada beberapa prasasti penetapan sima adalah saphata yang berarti sumpah atau kutukan meskipun tidak semua prasasti yang ditemukan memuat unsur ini. Dalam hal ini, sapatha merupakan sumpah atau kutukan yang ditujukan bagi para pelanggar, yaitu orang-orang yang berani merusak prasasti atau merubah aturan-aturan yang terdapat didalamnya. Dalam prasasti-prasasti Indonesia kuna, terdapat jenis sapatha yaitu; yang berupa unsur sapatha pendek dan unsur sapatha panjang, yang biasanya terletak pada bagian akhir isi prasasti. (Bakker;1972;15).

Pelaksanaan upacara dimulai dengan pengucapan mantra dan sumpah atau kutukan, yang kemudian dilanjutkan dengan memotong leher ayam yang dilandaskan pada sang hyang kulumpang, dan membanting telur pada 
sang hyang watu sima, dan menyalakan api pemujaan. Doa dan kutukan yang diucapkan oleh Sang Hyang Makudur tersebut disertai pengucapan mantra-mantra dan membakar kemenyan pada pedupaan yang telah disiapkan. Upacara ini mengandung arti magis simbolis, dan kekuatan magis ini ditujukan kepada siapa saja, apabila dikemudian hari melanggar ketentuan sima tersebut. Salah satu prasasti yang memuat pernyataan ini adalah prasasti Pañgumulan 824 Æaka sebagai berikut:

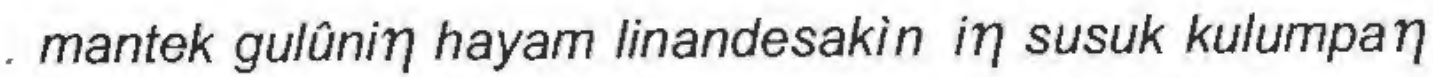
mamantingakan hantlû i sa $\eta$ hya $\eta$ watu sima mangganangi saK hya $\eta$ Brahma ri $\eta$ susuk kadyângganing hayam pjah dan waluy mahurip, kadi Iwir nikang hantlû remuk catasimna, kadi pernnah sa $\eta$ hya brahma tumunui ika $\eta$ kayu saka gegonan hila $\eta$ gseng tanpa hamban hawu kerir, mañkana ikana $\eta$ ua $\eta$ nganyaya asi $\eta$ umulah ulah iki wañua i pañgumulan sinima rakai wantil ....... (Darmosoetopo; 1991;18).

Sumpah dan kutukan itu diucapkan dengan jelas dan terdengar oleh semua yang hadir, diharapkan yang mendengarnya tidak akan berani melakukan pelanggaran (Haryono;1978;13-1). Disebutkan pula nama-nama dewadewa Hindu, arwah leluhur, dan kekuatan-kekuatan gaib,untuk menyaksikan ketetapan prasasti serta memberikan hukuman bagi mereka yang melanggarnya. Ada beberapa sarjana yang pernah menulis tentang sapatha yang terdapat dalam prasasti ini, diantaranya adalah Hariani Santiko dalam disertasinya yang berjudul Kedudukan Bhatari Durga di Jawa Pada abad X-XV Masehi. Pada halaman 149-153 dalam disertasi tersebut terdapat tabel prasasti-prasasti yang memuat unsur sapatha terutama yang menyebut nama Durggâdewi. Di dalam disertasi Edi Sedyawati yang berjudul Pengarcaan Ganesa Masa Kadiri dan Singasari. Sebuah Tinjauan Sejarah Kesenian, pada halaman 512-513 terdapat darftar prasasti yang memuat saphata disertai nama raja-raja yang disebutkan dalam prasasti tersebut.

Dalam tulisan singkat ini tidak akan dituliskan semua prasasti yang memuat unsur sapatha tersebut, namun hanya akan diuraikan 6 buah prasasti yang 
ditemukan di Jawa dan sebuah prasasti yang dikeluarkan pada masa Sriwijaya. Diantara prasasti yang memuat unsur sapatha yang ditemukan di Jawa adalah prasasti Kuti, Wuatan Tija, Lintakan, Sanghyang Tapak, Kembang Arum dan Adan-adan. Sementara prasasti dari kerajaan Sriwijaya yang memuat tentang Sapatha diantaranya adalah prasasti Kota Kapur, prasasti Karang Brahi, prasasti Palas Pasemah, prasasti Bungkuk dan prasasti Boom Baru. Dan sebagai contoh yang akan dikemukakan di sini adalah prasasti terbaru yaitu prasasti Boom Baru.

\section{Prasasti-prasasti dari Jawa:}

Prasasti Kuti 762 Caka : (Sarkar; 1971;83)

10. a. 4 ....... rumuddharuddha ra ${ }^{\circ} a$ ni ajòa nira pâduka úri mahârajâ, juah tasmat.

b. 1 karimaknanya, libokna ri sang hyang delim er; sanghapin dening vuhaya, yan,mara ring tgal, sambirrein.

2 ring glap; bvangakna dening alivâvar; utalakna dening alisyus; pulirakna dening devatâ,

3 sakitana dening pisaca, banaspati dingin, sanak; pulirakna dening deva rakªsa, dmakin ing macan;

4 yan, para ring tgal, manimvakna sungga vlah, yan, maparaparan, mapagakna muk; manaòdungakna ruyung avuk;

11. a. 1 simpal, simpalin; pangalorakna pangdulakna dening deva rakªsa, vvil, detya dânawa, samangkâ

2 na sapâthani sang makalambi haji, yavat.

- Prasasti Wuatan Tija 802 Saka : (Sarkar;1971;253-254)

b. $\quad 7$........ yâpuan hana anyâya lumangkahanang úasana langghanâ i ajòa haji /lumaburra ike vanua i vu(a)tan tija / sima anugraha œri mahârâja ryy anak nira

8 dyah bhûmijaya / ndah pangan ta kamung hyang duduk hatinya savvittakan vtangnya rantan ususnya udulakan pahungnya vituakan dalimmanya / tampyal i viravan mevahi

9 i tangannan yan para ing alas pangannin ning mong patukan ning ulâ / pulirakna ni devamanyuh / yan hana ya 
i tigal pangannin ning glap panganan ning vuil sang pamungvan

sampalaning râk asa arah kita hyang kuikagargametri kurump(u) pâtaòjalâ suvuk lor kidul kuluan vetan buangakan ing âkâúa/ salamvitakna ning

c. 1 hyang kabeh tibâkina ing samudra klammakna ing

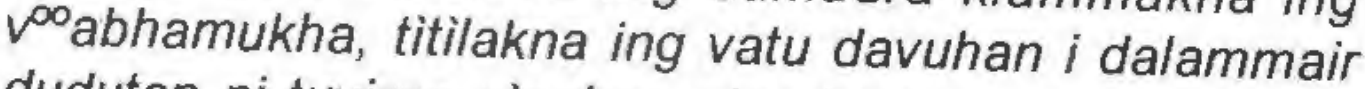
dudutan ni tuviran sipahan ni vuhaya angkinan matya ikanang vang anyâ

2 ya ahamingana havu kerir upadravâ ing devata kadi syuh nikâng hant ilu hayam tan baluy matpung umiliha ing naraka tumiba ing mahârorava hitipan ni ka

3 vah saying makingkara i vulatta kita hyang candrâditya mangkana ulih hana nikanang manyâya langghanâ i ajòa haji asing lumibura ikeng vanua i vuatan tija sima ......

Terjemahan:

b. 7 ....... Jika ada orang tidak jujur melanggar tempat berdirinya perintah raja, hancurlah penduduk Wuatan Tija (jika menggangguo tanah perdikan anugerah Sri Maharaja untuk anaknya yaitu

8 Dyah Bhumijaya. Kemudian makanlah (perintah ini, artinya kerjakanlah) olehmu hai dewa, keduk hatinya, anting perutnya, putuskan ususnya, betot tulangnya, keluarkan jeroannya, pukul sisi kirinya dan

9 sisi kanannya. Jika ia pergi ke hutan, hendaknya dimakan harimau, digigit ular, dipuntir oleh dewa kemarahan. Jika ia ada di ladang, hendaknya disambar petir, dimakan oleh dewa api

10 dikoyak-koyakkan oleh raksasa. Ai dewa-dewa Kusika, Garga, Maitri, Kurumpu, Patanjala, disembur angin ke utara, selatan, barat dan timur, buanglah ke angkasa, dilemparkan oleh

c. 1 dewa semua. Jatuhkan di samudera, tenggelamkan di (penggorengan neraka) dengan bentuk kepala kerbau, jejalkanlah di sela-sela batu bendungan. Di dalam air 
hendaknya ia di cabik-cabik dijadikan sisa makanan buaya, begitulah matinya orang yang durhaka

2 dipermainkan oleh abu sebagai siksaan dewata; seperti hancumya telur ayam yang tak dapat disatukan kembali. la dipilih dibawa ke neraka dan dijatuhkan di maharorawa (nama bagian neraka) dijadikan kerak kawah

3 oleh pelayan dewa Yama. Wahai dewa Matahari dan Bulan, lihatlah itu. demikianlah nasib orang yang durhaka dan berani melanggar perintah raja dan orang yang merusak desa Wuatan Tija, sebuah desa perdikan ..... (Suhadi dan Sukarto; 1986;106-112)

- Prasasti Lintakan 841 Saka: (Sarkar;1971;169):

18 yadeyanyu

19 i patiya te panoliha i vuntat, te tinghala i likuran, tampyal, $i$ virangan, uvahi $i$ tingannan, tutuh tuòdunya blah tapâlanya sbittakan, vtangnya rantan, usûsnya vtuakan, dalammanya duduk hatinya pangan, daging

20 nya inum, râhnya tihir ppddakan, vkasakan havu kerir, tibâkan ing mahârorava klân, i kavah sang yama saluir ni(ng?) lara hidapannya, kadi lavas sang hyang candrâditya pumungluhi aòdabhuvana mangkanâ lavasanya

21 n, tmuakan, sângsara avaknya rabinya anaknya putunya puyutnya anggasnya nâhan, li(ng)nira panghanâkan, sapatha mathr, mamantingakan, hantlu mankk gulu ning hayam, ling nira indah bhapâra kadyanggânike hantlû tan va

22 luy, i kurunganya samangkana ikeng hayam, tan, valuyâ matpung gulûnya mangkanâ tmahanani kanangnguang umulahulah suúuk ning kudur, sângsârâ ataya úakulagotranya kavaih, ikana sang masima svasthâ dirghâyu ${ }^{\circ} a$, astu(.) 
- Prasasti Sanghyang Tapak 952 Saka: (Poesponegoro;1984;362)

Prasasti ini berisi tentang adanya daerah larangan di sebelah timur Sanghyang Tapak, berupa sebagian dari sungai yang dinyatakan tertutup untuk segala macam penangkapan ikan dan penghuni sungai lainnya. Barang siapa yang melanggar ketentuan itu akan kena sumpah. Pada bagian yang meminta kesaksian para dewa dan leluhur disebutkan, sumpah yang bakal diterima kepada para pelanggar ialah; terbelah kepalanya, terminum darahnya, ter potong-potong ususnya, terhisap otaknya dan terbelah dadanya. Sumpah itu berlaku sepanjang masa dan mungkin pengaruhnya secara tidak disadari masih terasa sampai sekarang, karena orang yang tinggal di sekitar tempat itu pun jarang yang berani mandi di situ.

- Prasasti Kembang Arum 1223 Saka: (Santiko;1987;481)

Bagian belakang

8 ....... pamangmang sapatha samaya mami ri kita yavatikang vvang tan magçm tan mangmit irikang sang hyang râjânugraha patyananta

9 Yakamung hyang deyânta t patiya tarung ring pangadgan tâmpyal ring kivan tutuh tundanya panga(n) dagingnya rantan ususnya dudut hatinya vçtvakçn dalmanya langgasanya sivukapala

10 Nya cucup utçknya cucup sumsumnya makngkana yan paring tgal sambçr ning glap halapning pamungvan yan parengalas dmakning mong patukning ulâ bisa yan pareng vai pasukananing tuviran

11 Sanghapning vuhaya avuka tanţ̧mva sama liputning dhirâ vulangunan vçkanakrabinya tke sakula santananya jah tasmat tabvat karmmaknanya pçpçdakçn pranantikâ de kadi lava sang hyang câ

- Prasasti Adan-Adan 1223 Saka :( Kartoatmodjo;1994;3-4) $X V I b$.

3 tasmât kabwat karmma knanya, patyananta ya denta kamu hya kabeh de a tat-pati-

4 ya, yan-aparanparan, humalinta $\eta$ rm tgal, sahutn deniñ-ulâ mandi, yan pare nalas 


\section{XVIIa.}

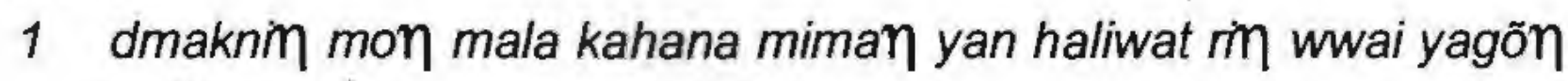
sañhapn-de

2 nim wuhaya, mumul, tuwiran, yan haliwat rì hawan gõ kasopa wula-

3 nun haliiiññõnayan hudan sambrn denm glap yan hana niñ-umahnya ka

4 tibâna bajrâgni tan p-warª liputn gsnana de sạ hyạ-âgni wehn bhasmi-

$X V I I b$.

1 bhûta saha drwyanya panoliha rin wuntat tarum riòadgan tâmpyal rin kiwa-

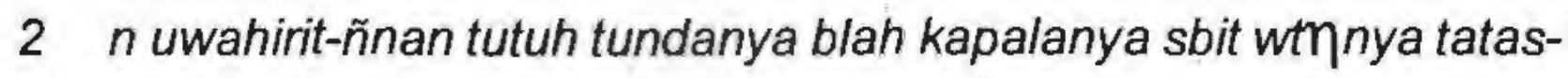
dada-

3 nya btwaๆkn dalmanya panan dagmnnya inum râhnya athr ppdakn we-

4 hi prânântika byõnakn rinakasa tibâkn rì mahârorawa, astu astu astu. //

\section{Prasasti dari Sriwijaya}

Prasasti Boom Baru; (Kartoatmodjo;1994;3)

Prasasti menggunakan bahasa dan huruf Melayu kuna, berasal dari sekitar akhir abad VII Masehi.

1 ... (niuja) rim droha (ka)....

2. tida ya bhakti tatwa arjâwa dy-aku dnan...

3 wunuh ya sumpah ni(suruh) tâpik-ya ...œriwija)

4 ya dñaò gotra santanânya...

5 maka lañit urang maka sakit maka gila...

6 upuh tûwa kas-han wasikaraòa itye (wamadio.

7 pulanka yan muah yan dosanya muah.

8 kadaci ya bhakti tatwa arjâwa dy-aku.

9 . datua santi muah (kawuatanya) dnan gotra (santananya) 
10 sam $^{\circ}$ ddha swastha niroga nirupdrawa subhik a muah ya wanunan

11 ya parâwis //O//

Terjemahan

1 (dikatakan) durhaka..

2 (apabila) ia tidak bakti dan tunduk (bertindak lemah lembut) kepadaku dengan..

3 dibunuh ia oleh sumpah dan di(suruh) supaya ia hancur oleh... (CErivija)

4 ya dengan sanak keluarganya..

5 menyebabkan orang hilang ingatan; menyebabkan orang sakit dan menyebakan orang gila

6 racun dan tuba, mengguna-gunai orang supaya jatuh cinta (kasihan), mengguna-gunai orang supaya tunduk pada kemauannya dan demikian selanjutnya...

7 kembali ke asalnya lagi ke dosnya lagi...

8 tetapi apabila setiap kali ia berbakti dan tunduk kepadaku...

9 dan taat kepada kedudukan raja ia akan menemukan kembali perbuatannya

10 kesentausaan dan keselamatan, sehat walafiat, bebas mala petaka, makmur

11 seluruh negara //O//

4. Pembahasan

Dari contoh tujuh prasasti di atas, dapatlah diketahui bahwa pada umumnya hukuman yang menimpa pelanggar ketetapan prasasti antara lain adalah:

a. Ancaman-ancaman agar si pelanggar akan mendapat malapetaka yang mengerikan seperti halnya ayam yang telah terpisah kepala dari badannya. Hancur lebur seperti telur yang telah pecah, dan seperti kayu yang menjadi abu karena hangus terbakar. Bahkan jika pergi ke hutan akan di makan ular berbisa dan diterkam harimau, jika pergi ke ladang akan disambar petir sekalipun musim kemarau, jika pergi ke bendungan atau sungai akan tenggelam di makan buaya.

b. Ancaman-ancaman supaya menderita penyakit yang tidak bisa disembuhkan, mengalami kelahiran kembali berulang kali, memperoleh petaka dan lain-lainnya. 
c. Ancaman hukuman bagi si pelanggar, isteri, anak, cucu, buyut, bahkan sampai seluruh keturunannya sepanjang masa.

d. Hukuman dari para hyang (bhatâra), raksasa, dan tokoh-tokoh lain. yang disebut dalam prasasti, dengan cara tubuhnya disakiti dan di koyak-koyak. (Santiko; 1987;144).

e. Dan bagi yang tidak melanggar sumpah dan mentaati isi prasasti tersebut, akan mendapat karunia dan keselamatan.

Selain itu, ancaman kutukan juga berlaku bagi mereka yang tidak taat dan memberontak kepada raja, terutama pada saat dilakukan peperangan maupun penaklukkan atas suatu daerah tertentu yang menyebabkan dikeluarkannya suatu prasasti peringatan. Kutukan semacam ini tentunya ditujukan kepada warga daerah taklukan, agar tidak melakukan tindakan yang dapat menyulitkan kerajaan yang telah berhasil menaklukkannya, misalnya melakukan pemberontakan dan penyerangan kembali terhadap kerajaan tersebut.

Pengungkapan sapatha dalam suatu prasasti dapat mencerminkan kekuasaan suatu kerajaan atas daerah-daerah bawahan dan juga daerah taklukan. Di lain pihak, dimuatnya sapatha dalam prasasti juga mencerminkan adanya kekawatiran dan ketakutan suatu kerajaan mendapat serangan balik. Oleh karena itu, suatu kerajaan menganggap perlu menyertakan sapatha dalam prasasti yang ditetapkan, dengan menyebutkan ancaman-ancaman yang terkesan menakut-nakuti siapa saja yang melanggarnya. Jika sampai pelanggaran terhadap ketentuan prasasti terjadi, maka di setiap tempat atau dimanapun si pelanggar berada, bahaya dan mala petaka akan selalu mengancam. Pelanggar tidak akan merasa tenteram di segala tempat, karena ancaman-ancaman yang telah disebutkan dalam prasasti seolah-olah akan benar-benar menimpa dirinya. Hal inilah yang mungkin diharapkan dapat mencegah terjadinya pelanggaran terhadap prasasti. Isi sapatha yang menggambarkan penyiksaan tanpa ampun terhadap pelanggar, mungkin juga merupakan gambaran tentang hukuman yang harus diterima dari kerajaan yang mengeluarkan prasasti itu. Dengan adanya sapatha tersebut tentunya diharapkan pula tidak akan pernah lagi terjadi tindak kejahatan, sehingga kerajaan menjadi aman dan damai. 


\section{KEPUSTAKAAN}

Bakker S.J; 1972; IImu Prasasti Indonesia Cetakan ke 4; Yogyakarta: Jurusan Sejarah Budaya IKIP Sanata Dharma

Boechari; 1985/1986; Prasasti Koleksi Museum Nasional Jilid I; Jakarta: Proyek Pengembangan Museum Nasional.

Darmosoetopo, Riboet; 1991; Dampak Kutukan dan Denda Terhadap Penetapan Sima Padja Masyarakat Jawa Kuna; Analisis Hasil Penelitian Arkeologi, Analisis Sumber Tertulis Masa Klasik; Jakarta : Proyek Penelitian Purbakala; Depdikbud

Haryono, Timbul; 1978; Gambaran Tentang Upacara Penetapan Sima; Yogyakarta: Fakultas Sastra dan Kebudayaan UGM.

Atmodjo, S. K (1994). Beberapa Temuan Prasasti Baru Di Indonesia. Berkala Arkeologi, 14(2), 1-5. https://doi.org/10.30883/jba.v14i2.630

Poesponegoro, Marwati Djoened dan Nugroho Notosusanto; 1984; Sejarah Nasional Indonesia II; edisi ke-4, Jakarta: Depdikbud, Balai Pustaka

Santiko,Hariani; 1987; Kedudukan Bhatari Durga di Jawa Pada Abad X - XV Masehi; (Disertasi); Jakarta : Program Pasca Sarjana UI.

Suhadi, Machi dan M.M. Sukarto K; 1986; Laporan Penelitian Epigrafi Jawa Tengah No. 37; Jakarta: Proyek Penelitian Purbakala Depdikbud.

Suhadi, Machi; 1993; Tanah Sima Dalam Masyarakat Majapahit; (disertasi); Jakarta : Program Pasca Sarjana UI.

Sedyawati, Edi; 1994; Pengarca an Ganesa Masa Kadiri dan Singhasari. Sebuah Tinjauan Sejarah Kesenian; (Disertasi); Seri LIPI-RUL; Jakarta: LIPI - Ecole Francaise D'ectreme Orient . 